\title{
O PROBLEMA FUNDAMENTAL DA EDUCAÇÃO COMPARADA
}

EDUCAÇÃO COMPARADA é hoje uma disciplina que vem adquirindo prestigio crescente nos currículos dos cursos de formaçāo de professôres. Entre nós ela está fazendo parte dos planos de estudos universitários, desde a fundaçāo do Instituto de Educaçāo .em 1934.

A obra de base que tem servido a êsses estudos é a "Comparative Education" de I. L. Kandel, célebre professor da Universidade de Colúmbia, obra hoje traduzida por N. F. Abu-Merhy, para a coleçāo pedagógica dirigida por Fernando de Azevedo na Companhia Editôra Nacional de São Paulo.

Pensamos entretanto que se faz indispensável um ajustamento da compreensāo da Educaçāo Comparada, razāo por que apresentamos neste artigo uma série de considerações.

Kandel manifesta, desde o prefácio de sua citada obra, uma decidida preferência pelo tratamento interpretativo históricosocial da matéria, rejeitando, por considerações de ordem prática, - tratamento descritivo quantitativo, em virtude do que êle chama a dificuldade de reduçāo dos dados estatísticos a unidades comuns, bem como da de unificação da terminologia usada pelas instituições escolares dos diferentes paises. Acresce ainda que, na introduçāo do seu trabalho, Kandel apresenta uma lista de temas que êle considera "almost universally identical", lista essa em que se incluem, dominantemente, problemas da filosofia e da politica que influenciam a organizaçāo das instituições educacionais.

A linha geral da obra de Kandel é, entretanto, uma discussāo de problemas educacionais e escolares daqueles assuntos, em capitulos que constituem verdadeiras monografias.

Num artigo escrito para a "Encyclopedia of Modern Education" editada por H. Rivlin e H. Schueler, o mesmo Kandel observa o interêsse crescente pelo estudo dos sistemas educacionais estrangeiros e a utilizaçāo da Educaçāo Comparada para a construção indutiva da filosofia da educaçāo.

Milton Rodrigues, fundador dos estudos de Educação Comparada na Universidade de São Paulo, o único autor brasileiro de um compendio dessa matéria, abre seu livro propondo como "definiçāo provisória" dêsse campo de estudos, que êle seja enten- 
dido no sentido de "a história contemporânea da educaçāo": desenvolvendo em seguida uma exposiçāo critica do que acabava de definir e levando à compreensāo da Educaçāo Comparada como elemento de ligação entre a história contemporânea e a filosofia da educaçāo.

Mas no desenvolvimento de seu plano de estudos, Milton Rodrigues alarga o sentido do adjetivo contemporânea, forçado pelas necessidades de buscar para a fundamentaçāo do estado atual das idéias educacionais e das instituições pedagógicas, muito além da conceituação clássica de "história contemporânea". De fato, estudando, por exemplo, os problemas inglêses, vê-se obrigado a recuar até a época da Reforma; tratando da França, remonta ao tempo de Descartes; no capitulo a respeito da Itália vai até Vitorino da Feltre. E, mesmo na parte referente aos Estados Unidos, "país de história recentissima", nāo pode deixar de referir-se à época da colonizaçāo.

Há uma terceira obra importante publicada sob a denominaçāo de "Comparative Education" por Nicholas Hans da Universidade de Londres.

Hans nāo foge também à interpretaçāo dada à Educaçāo Comparada por Kandel e Milton Rodrigues, pois escreve: "The analytical study of these factors (a herança do passado e ideias do futuro) from a historical perspective and the comparison of attempted solution of resultant problems are the main purpose of Comparative Education".

O plano do livro de Hans é especialmente significativo como interpretação histórico-social dos problemas educacionais. Aborda êle numerosas questões tais como fatores lingüisticos, religiāo, socialismo etc. e, quando entra a descrever as condições legais vigentes nos sistemas educacionais modernos, as relações e interpretações continuam a ser dominantemente histórico-sociais.

Um outro tipo de estudo da Educaçāo Comparada, apresentado num livro cujo título nāo deixa transparecer seu conteúdo, foi - feito por Horácio Rivarola, da Universidade de Buenos Aires, no seu "Legislación escolar y ciencia de la educación". Tomando como base a legislação escolar argentina, Rivarola revela entretanto, desde o prólogo do livro, a preocupaçāo de dar "como objeto de su estudio las relaciones entre la organización política y social de cada "pueblo y época, y' la organización de la instrucción pública...

Observando, finalmente o ponto de vista de Emma Perez, da Universidade de La Habana, encontramos na sua "Educación Comparada", apesar da referência às diversas maneiras pelas quais - assunto tem sido encarado desde seu batismo pelos pedagogos alemāes (ciência geral da educaçāo), e pelos americanos modernos (estudo da pedagogia estrangeira), posiçāo semelhante adotada por ela na compreensão dos fins a que se destina a disciplina: 
"conocer los resultados que arrojam la ciencia educativa en los más característicos países del mundo, a base del estudio comparativo de las causas que han producido los sistemas de educación en los mismos".

Essa rápida observaçāo sôbre os pontos de vista em que se tem colocado a generalidade dos autores mais significativos que trataram a "Educaçāo Comparada", permite-nos a proposiçāo de um conceito mais adequado para ela. Pensamos que está mal colocada sua posiçāo como disciplina de estudo nos currículos. A Educaçāo Comparada é, de fato, especialmente, um método de apresentação ou de abordagem dos problemas educacionais em geral e dos escolares em particular, em funçāo dos dados históricos, sociais ou estatísticos, bem como dos demais dados que podem, de algum modo, contribuir para esclarecer as questões tomadas.

Parece-nos que nāo tem sentido como ramo de estudo o que de fato é método de abordagem $e$, se atentarmos para o trabalho comum dos estudos educacionais, veremos que todos êles, ou pelo menos a sua generalidade, sāo feitos com permanente necessidade de comparação.

A comparaçāo, como um dos elementos fundamentais do método científico estará sempre presente em todos os tratamentos de problemas, quer pelas necessidades de melhor clareza e riqueza de exposição, quer pelas de pesquisa de novos conhecimentos. Assim 2 por isso, no ensino ou na pesquisa dos assuntos educacionais, ela nāo passará de um aspecto metodológico, pela simples razāo de que, quem ensina ou pesquisa, lança māo naturalmente, a cada passo, das comparações.

Para corroborar nosso ponto de vista, chamamos a atençāo para uma passagem do artigo de Kandel a que nos referimos acima: "Such an approach has become all the more necessary at the time when education is more than ever a concern of the national state..." Os grifos sāo nossos, pois se fôssem dêle, nāo haveria por certo necessidade de apresentar a discussāo dêste artigo. Corrobora ainda êsse nosso ponto de vista, o fato de fazer parte inerente da Educação Comparada, a escolha de um têrmo de comparação (elemento genuinamente metodológico), seja aquêle para o qual se deseja melhor esclarecimento, seja aquêle que, melhor conhecido já, vai servir para facilitar a compreensāo de outro.

\section{J. QUERINO RIBEIRO}

Professor de Administraçāo Lscolar e Educacão Comparada da Faculdade de Filosofia, Ciéncias

e Letras da Universidade de São Paulo. 
REFER E N C IA BI B L I O GRA F I C A

KANDEL (I. L.). - Comparative Education. 1933. The Riverside Press Cambridge.

KANDEL (I. L.). - Comparative Education. In "Encyclopedia of modern education". Rivlin (H.) e Schueler (H.) (Editors) The Philosophical Library of New York City. 1943.

RODRIGUES (M. C.S.). - Educação Comparada. 1938. Companhia Editôra Nacional. São Paulo.

PEREZ (E.). - Educación Comparada. 1945. Cultural S. A.. Habana.

RIVAROLA (H.). - Legislación escolar y ciencia de la educación. 1944. Tercera edición. Libreria y editorial "El Alteneo". Buenos Aires.

HANS (N.). - Comparative Education. 1950. Routledge \& Kegan Paul. London.

DEFODON (C.). - Marc Antoine Jullien. In "Noveau dictionnaire de Pédagogie" de F. Buisson. 1911 - Hachette. Paris. 